\title{
COMPETÊNCIAS SOCIOEMOCIONAIS NAS POLÍTICAS DE AVALIAÇÃO EM LARGA ESCALA E CURRICULARES: UM AJUSTE À FORMAÇÃO HUMANA VOLTADA PARA O MERCADO DE TRABALHO PRECÁRIO*
}

\author{
Amanda Melchiotti Gonçalves \\ Simone Sandri \\ Jaqueline Bonfim de Souza Lima \\ Thays Trindade Mayer
}

\section{Apresentação}

O tema do capítulo refere-se aos desdobramentos da noção de competência socioemocional nas atuais políticas de avaliação em larga escala e curricular para educação básica, no Brasil. Para discutirmos essa temática, levantamos duas premissas. São elas: as demandas por competências socioemocionais são decorrentes das atuais configurações do mercado de trabalho; na função de promotor do consenso social sob a ótica do mercado, o Estado educador, sentido gramsciano, insere as competências socioemocionais no contexto das políticas educacionais. A pesquisa foi qualitativa de cunho bibliográfico e documental. Analisamos documentos de autoria do Banco Mundial, Instituto Ayrton Senna e Movimento pela Base Nacional Comum Curricular, com apoio da organização "Center for Curriculum Redesign" (CCR). Como principais resultados, analisamos que as competências socioemocionais contribuem para limitar o processo de formação humana, uma vez que resumem as condições de sociabilidade, bem como psíquicas de cunho emocional aos ditames do mercado.

Nesse texto analisamos os desdobramentos da noção de competência socioemocional no contexto das atuais políticas de avaliação em larga escala e curriculares para a Educação Básica, no Brasil.

Para discutirmos as competências socioemocionais partimos do fundamento que originou a noção competência, isto é, as mudanças no mundo do trabalho ocasionadas pela reestruturação produtiva em desenvolvimento desde os anos de 1970, nos países do capitalismo central e, anos de 1980, nos países periféricos, como é o caso do Brasil.

A formação do trabalhador, a partir de competências práticas decorrentes das necessidades de reorganização do trabalho (reestruturação produtiva ou acumulação flexível ou toyotismo), contribuíram para a definição de um rol de competências a serem desenvolvidas pelos chamados trabalhadores polivalentes, tais como: flexibilidade, autonomia, realização de várias tarefas, relacionamento interpessoal, resolução de conflitos, capacidade de se antecipar aos problemas entre outras capacidades que

*DOI - 10.29388/978-65-86678-87-1-0.f.100-113 
diferenciavam o trabalhador toyotista do perfil de trabalhador taylorista (técnico especialista em uma área/atividade específica).

No caso do Brasil, a partir dos anos de 1990, um conjunto de competências gerais para a formação de trabalhadores e/ou para novas gerações de trabalhadores, passou a nortear as reformas curriculares e de avaliação em larga escala para a educação básica. Recentemente, a proposta de formação para a educação básica, passou a incorporar, no currículo e na avaliação em larga escala, uma "nova" competência, denominada de socioemocional.

A principal questão a ser discutida, nesse artigo é a seguinte: quais são os principais desdobramentos da noção de competência socioemocional no projeto de formação humana, materializado nas atuais políticas de avaliação em larga escala e curricular, no Brasil?

Para analisarmos os desdobramentos decorrentes da noção de competência socioemocional no contexto das políticas educacionais, desenvolvemos esta pesquisa qualitativa de cunho bibliográfico e documental, com base nas seguintes premissas teórico-metodológicas:

A primeira premissa parte da configuração atual do mercado de trabalho que tem expandido as ocupações precárias, instáveis, temporárias e informais. Portanto, para lidar com situações adversas ligadas às condições de sobrevivência dos sujeitos, a escola, além de desenvolver competências cognitivas, também deveria ajustar a formação dos sujeitos de acordo com possíveis "competências socioemocionais", capazes de levá-los a "resolver" as adversidades e contradições impostas pelas atuais condições do mercado de trabalho.

A segunda premissa que consideramos na nossa análise, parte da concepção gramsciana de Estado educador. Para Gramsci, o Estado também tem uma função educativa, pois busca, pelo consenso social, ratificar a lógica do grupo economicamente e politicamente predominante na sociedade.

Sobre os encaminhamentos metodológicos, destacamos os seguintes: Leitura e análise do referencial bibliográfica referente às dimensões do tema desse capítulo.

Fundamentadas na ideia de que os documentos são efeitos da realidade e expressão das determinações históricas (EVANGELISTA, 2012), selecionamos a seguinte base empírica: "Competências e Empregos: Uma Agenda para a Juventude", de 2018, Banco Mundial; "Competências socioemocionais em políticas públicas”, de 2016, Instituo Ayrton Senna; Documento Orientador da Base Nacional Comum Curricular (2017 e 2018), MEC; "Dimensões e Desenvolvimento das competências Gerais da BNCC", de 2018, do Movimento pela Base Nacional Comum Curricular, com o apoio da organização - "Center for Curriculum Redesign" (CCR). Nesses documentos, identificamos os principais conteúdos para a definição do recorte temático desse texto, a relação entre competências socioemocionais e o ajuste da formação humana ao atual e precário mercado de trabalho.

Com a intenção de sistematizar os principais resultados da discussão dessa questão, organizamos esse artigo em duas seções:

Na primeira seção, consideramos como questão subjacente para nossa análise, a noção gramsciana de Estado educador, pois, entendemos que a inserção das 
competências socioemocionais no contexto da avaliação em larga escala é um mecanismo para ajustar a formação humana à atual configuração do mercado de trabalho, sendo o Estado um dos principais condutores desse processo. Tal ajuste, via avaliação em larga escala, intensifica o controle da formação ofertada aos sujeitos, sendo este controle estendido também às questões comportamentais de cunho social e emocional.

Na segunda seção, com base na análise dos documentos que compõem a base empírica da nossa pesquisa, analisamos alguns excertos dos documentos a fim de demonstrar os desdobramentos da noção de competência socioemocional no contexto curricular.

Nas considerações finais, confirmamos os elementos destacados nas premissas anunciadas para nossa análise. Destacamos também que as competências socioemocionais intensificam o projeto de formação humana referenciado pelo mercado de trabalho, limitando, portanto, as potencialidades de formação dos sujeitos para além dos ditames mercadológicos.

\section{As competências socioemocionais no contexto da avaliação em larga escola: atualização dos instrumentos de controle do Estado educador}

Para análise da temática desse texto, consideramos como questão subjacente a concepção gramsciana de Estado, isto é, a ideia de que o Estado, no sentido stricto, exerce um papel de educador por contribuir para difusão da lógica cultural e política do grupo hegemônico economicamente e politicamente. Para Gramsci (2007), a:

Tarefa educativa e formativa do Estado, cujo fim é sempre o de criar novos e mais elevados tipos de civilização, de adequar a 'civilização' e a moralidade das mais amplas massas populares às necessidades do contínuo desenvolvimento do aparelho econômico de produção e, portanto, de elaborar também fisicamente tipos novos de humanidade. Mas como cada indivíduo singular conseguirá incorporar-se no homem coletivo e como ocorrerá a pressão educativa sobre cada um para obter seu consenso e sua colaboração, transformando em 'liberdade' a necessidade e a coerção? Questão do 'direito', cujo conceito deverá ser ampliado, nele incluindo aquelas atividades que hoje são compreendidas na fórmula 'indiferente jurídico' e sem 'obrigações' taxativas, mas que nem por isso deixa de exercer uma pressão coletiva e de obter resultados objetivos de elaboração nos costumes, nos modos de pensar e de atuar, na moralidade, etc. (GRAMSCI, 2007, p. 23-24).

No caso das atuais políticas de avaliação e de currículo para a educação básica, notamos a função educadora do Estado ao ajustá-las de acordo com as demandas do mercado de trabalho, estimulando, assim, para que tais demandas se tornem uma espécie de referência consensual para a formação humana. 
A educação brasileira, no bojo das reformas dos anos de 1990, assumiu um caráter político de vinculação aos interesses nacionais e transnacionais. De acordo com Sandri (2019), a Reforma do Aparelho do Estado, implementada pelo Ministério da Administração Federal e da Reforma do Aparelho do Estado (MARE), no Brasil, possibilitou a ampliação e a diversificação da atuação de instituições e/ou prestadoras de serviço educacionais privadas e/ou filantrópicas por meio das parcerias públicoprivado. Dessa forma, a reconfiguração estatal, no país, passou a ampliar o espaço para gestão das políticas sociais via setor privado.

Outra característica implementada a partir da reforma do Estado, foi a avaliação das políticas públicas. No caso da educação, as políticas de avaliação em larga escala têm incorporado algumas orientações internacionais, operando como instrumento de coleta de dados, diagnósticos e classificações de instituições e sujeitos de acordo com o desempenho nas avaliações.

A política de avaliação instituída a partir desse período, está associada a nova forma de gerir os recursos estatais e está em correspondência com as estratégias de consolidação dos propósitos da mundialização do capital. Ou seja,

A mundialização do capital incentivou a descentralização e movimentação de empresas e, consequentemente, de demanda por novas qualificações de trabalhadores que deveriam estar disponíveis em qualquer parte do globo, onde fossem instalar suas plantas e escritórios. Esse movimento impactou rapidamente o campo da educação, alardeando a necessidade de reformas para prover os estudantes com as competências e habilidades demandadas pelo setor produtivo, na esteira das proposições da Unesco sintetizadas no Relatório da Educação para o século XXI (UNESCO, 1998) (SHIROMA; ZANARDINI, 2019, p. 119).

A política educacional, entendida como constituinte da política social (DEITOS, 2010), engendra-se nessa reconfiguração política e econômica. Assim, o ordenamento ideológico das políticas educacionais opera nas "[...] condições sociais e psico-políticas necessárias à estabilidade socioeconômica" (DEITOS, LARA, 2019, p. 21).

Esse movimento é observado, especialmente, nos países da América Latina, como o Brasil, pois segundo Saes (2006), a partir da década de 1990, com a forte atuação das agências multilaterais, como o Banco Mundial (BM) e o Fundo Monetário Internacional (FMI), a América Latina fortalece sua relação de dependência ao capital internacional.

As reformas educacionais dos anos de 1990, portanto, foram justificadas pela necessidade de adequação dos indivíduos a ordem globalizante do século XXI. Vale lembrar, que a educação nessa perspectiva, é concebida "[...] como variável fundamental para a redução da desigualdade e da pobreza" (FIGUEIREDO, 2006, p. 105). Ao mesmo tempo, a subjetividade é enaltecida de modo a condicionar os indivíduos a subordinação de seus méritos. 
Norteado por essas ideias, o sistema de avaliações, no Brasil, tem sido organizado pelo Instituto Nacional de Estudos e Pesquisas Educacionais Anísio Teixeira (INEP), sendo uma autarquia federal, vinculada ao Ministério da Educação (MEC). O INEP destaca que as avaliações, como instrumentos de coletas de dados, que têm por objetivo "subsidiar a formulação de políticas educacionais dos diferentes níveis de governo com intuito de contribuir para o desenvolvimento econômico e social do país" (BRASÍLIA, 2020).

Seguindo o discurso de que a Educação de qualidade é o meio pelo qual se alcança o desenvolvimento econômico e social, a cartilha Sistema de Avaliação da Educação Básica (SAEB, 2019) anuncia que:

O sistema de avaliação da Educação Básica tem como objetivo diagnosticar a educação básica do País e contribuir para a melhoria de sua qualidade, oferecendo subsídios concretos para a formulação, a reformulação e o monitoramento das políticas públicas voltadas para a educação básica (BRASílIA, 2019, p. 4).

Os resultados oriundos das aferições em larga escala, tem norteado o trabalho pedagógico em função das exigências das avaliações externas. Para Luckesi (2005), diante da função classificatória, a avaliação se torna um instrumento estático e frenador do processo de desenvolvimento educacional. Para Afonso (2000),

\begin{abstract}
A avaliação normativa parece ser, portanto, a modalidade de avaliação mais adequada quando a competição e a comparação se tornam valores fundamentais em educação. Nesta modalidade de avaliação, os resultados quantificáveis (por exemplo, os que se referem ao domínio cognitivo e instrucional) tornam-se mais importantes do que os que se referem a outros domínios ou outras aprendizagens (AFONSO, 2000, p. 34).
\end{abstract}

Essa perspectiva de avaliação se fundamenta e se expressa a partir do modelo da sociedade capitalista, demonstrando como parte importante desse processo, a classificação e, consequentemente, a valorização a partir dos resultados. Assim, Luckesi (1995), aponta que a avaliação não é neutra e está ancorada num modelo de educação e de mundo observada a partir de uma prática pedagógica.

Para Zanardini (2008, p.22), o atual estágio do modo de produção capitalista "[...], exige e implementa processos e mecanismos de avaliação tendo em vista avaliar e controlar o sucesso ou o fracasso das proposições educacionais que implementa". Por meio das avaliações em larga escala, o Estado avaliador obtém dados para o processo regulação dos investimentos em educação, enaltecendo a importância da coleta de dados para regular não só os investimentos, mas também realizar o controle social. Segundo Zanardini (2008),

A avaliação educacional meritocrática ganha proeminência compondo o discurso ideológico do Banco Mundial que, por via do 
controle mediante avaliação, alcançaria a maximização do impacto da educação no crescimento econômico e na redução da pobreza. (ZANARDINI, 2008, p. 23).

No atual momento, o BM, uma das principais agências multilaterais, tem emitido documentos/relatório no sentido de reforçar essa perspectiva de avaliação como forma de aprofundar o projeto em curso, desde 1990, para a educação dos países da América Latina.

Para tanto, o BM reforça os argumentos de que para progredir economicamente, é necessário aperfeiçoar os sistemas de avaliação da aprendizagem dos estudantes, pois, segundo o BM é preciso "atuar com base na evidência para fazer as escolas trabalharem para todos os educandos; e alinhar os atores para fazer todo o sistema funcionar em prol da aprendizagem" (BANCO MUNDIAL, 2018, p. 3).

No relatório sobre o desenvolvimento mundial, intitulado "Aprendizagem para realizar a promessa da educação" (2018), o BM aponta que todos os esforços dos países desprendidos em prol das avaliações, determinam a sua condição de crescimento e desenvolvimento, ou seja,

\begin{abstract}
A recompensa desses esforços é uma educação que ajuda o crescimento e o desenvolvimento. Se for realizada com qualidade, a educação cura toda uma série de males da sociedade. Para os indivíduos, promove emprego, renda, saúde e redução da pobreza. Para as sociedades, impulsiona o crescimento econômico de longo prazo, incentiva a inovação, reforça as instituições e promove a coesão social. Porém, como mostram as evidências crescentes, são as habilidades adquiridas por meio da educação e não apenas o tempo despendido na escola que conduzem o crescimento e proporcionam aos indivíduos os recursos para o trabalho e para a vida (BANCO MUNDIAL, 2018, p. 4).
\end{abstract}

Sob esta ótica, para ajustar a formação humana às novas demandas do mercado de trabalho e "garantir" a "qualidade" da educação, a escola deveria atualizar o rol de competências a serem ensinadas aos sujeitos. Tendo o mercado de trabalho como referência, agrega-se ao discurso da qualidade educacional, a condição de a escola desenvolver competências socioemocionais.

Com base nos autores que fazem a crítica ao modelo de avaliação controladora/classificatória, conforme mencionamos anteriormente, pressupomos que a incorporação das competências socioemocionais ao sistema de avaliação e currículo estimularia a verificação e o controle de comportamentos, costumes, hábitos e possíveis reações e respostas dos sujeitos diante de situações de tensão, estresse, incertezas, conflitos, condição de convívio social e emocional.

Tais práticas avaliativas são comuns nos processos de seleção de mão de obra, quando os candidatos às vagas de emprego se submetem a uma bateria de testes, situações problemas e verificação das condições interpessoais. 
Consideramos que a inserção das competências socioemocionais nas políticas de avaliação e curricular, tendem a adequar o processo de ensino e de aprendizagem da educação formal à "lógica de recrutamento" utilizada pelas empresas. Por outro lado, o mercado de trabalho não contempla a todos, logo, as competências socioemocionais também estariam voltadas para ensinar o sujeito a sobreviver diante das condições de informalidade do trabalho.

A estrutura do mercado de trabalho, que se configurou a partir da reestruturação produtiva, descrita por Harvey (2002), com base nos estudos do "Institute of Personnel Management", demonstra que o grupo de trabalhadores do centro do mercado de trabalho, tem reduzido cada vez mais, pois são trabalhadores com estabilidade, qualificação mais complexa e grandes salários. Na primeira periferia que circunda o centro do mercado de trabalho, está o segundo grupo de trabalhadores, cujas ocupações apresentam grande rotatividade, com menores chances de seguir carreira e se qualificar. Por fim, o segundo grupo periférico, concentra a maioria dos trabalhadores que inclui "empregados em tempo parcial, empregados casuais, pessoal com contrato por tempo determinado, temporários, subcontratação [...], tendo ainda menos seguranças de emprego do que o primeiro grupo periférico" (HARVEY, 2002, p. 144).

Ao problematizarmos as competências socioemocionais, não desconsideramos a importância do desenvolvimento social e psíquico dos sujeitos, mas tensionamos a referência adotada, o mercado de trabalho, para definir competências socioemocionais. Isto é, resumir a sociabilidade e as condições psíquicas de cunho emocional às exigências do mercado.

No Brasil, a noção de competências esteve presente nas políticas de avaliação e curriculares para a educação básica, nos anos de 1990. Sendo que as atuais politicas de avaliação e currículo acrescentam a necessidade do desenvolvimento das "competências socioemocionais".

Sobre as atuais políticas avaliativas para a educação, destacamos, nesse texto, a parceria do Estado com o Instituto Ayrton Senna, que, por sua vez, articula-se a Organização para a Cooperação e Desenvolvimento Econômico (OCDE). Pois, por meio da identificação, do desenvolvimento e da avaliação de competências, se ambiciona "o desenvolvimento de um conjunto de competências necessárias para aprender, viver, conviver e trabalhar em um mundo cada vez mais complexo" (SENNA, 2016, p. 4). Com esse objetivo, o Instituto desenvolveu,

[...] um sistema de avaliação de competências socioemocionais que integra a avaliação formativa e somativa dessas competências às avaliações cognitivas existentes e possibilita, ainda, o cruzamento desses resultados com informações de contexto socioeconômico e ambiente de aprendizagem. O sistema, batizado de SENNA (Social and Emotional or Non-cognitive Nationwide Assessment), será disponibilizado para apoiar gestores e educadores na tarefa de formular, executar e reorientar políticas públicas e práticas 
pedagógicas destinadas a melhorar a qualidade da educação no Brasil (SENNA, 2016, p. 22).

Diante do exposto pelo Instituto Ayrton Senna, notamos uma reafirmação da necessidade de

[...] controle e enquadramento dos indivíduos nos parâmetros previamente estabelecidos de equilíbrio social, seja pela utilização de coações explícitas seja pelos meios sub-repticios das diversas modalidades de propaganda ideológica. A avaliação educacional será, assim, um instrumento disciplinador não só das condutas cognitivas, como também das sociais, no contexto da escola (LUCKESI, 1995, p. 32). [Grifos nossos].

A política de avaliação como "instrumento disciplinador" da conduta cognitiva, agora, da conduta socioemocional, transformam as necessidades básicas de aprendizagem em habilidades para lidar com as incertezas decorrentes das contradições dessa sociedade, contribuindo para minimizar a carga de criticidade dos sujeitos perante esta sociedade, desse modo,

[...] os instrumentos essenciais de aprendizagem (domínio da leitura, da escrita, do calculo, das noções básicas de saúde, etc.) convertemse em "destrezas" ou habilidades imediatas para a sobrevivência social, bem próximas da ideia de que o papel da escola é prover conhecimentos ligados à realidade imediata do aluno, utilizáveis na vida prática, sem compromisso da escola com o desenvolvimento de formas superiores de pensamento (LIBÂNEO, 2013, p. 61).

A educação relacionada às competências socioemocionais, segundo o discurso dos defensores desta perspectiva, pode ser um dos caminhos para a melhoria na qualidade da educação.

Diante dessa perspectiva, notamos que a relação entre avaliação, qualidade e habilidades socioemocionais perpassa pelas políticas e programas de como uma posição ideológica, que segundo Pereira (2016) "buscam construir um projeto hegemônico de educação, único e universal, centrado nos resultados dos processos de verificação e mensuração, impulsionando uma gestão gerencial meritocrática subsumida ao ethos mercadológico" (PEREIRA, 2016, p. 17).

A noção de competências socioemocionais no contexto da avaliação em larga escala ratifica o controle, a padronização de comportamentos a serem verificados por testes. Para Abatti (2019), a articulação entre as competências socioemocionais e a política de avaliação fundamentam-se no discurso de mercantilização da educação, de modo a classificá-la como um produto e não como um direito. Como forma de exercer seu papel de educador, no sentido gramsciano, o Estado incorpora as competências socioemocionais nas politicas educacionais. 


\section{Noção de competência socioemocional como mecanismo de atualização da formação humana voltada para o mercado de trabalho precário}

No contexto das atuais políticas curriculares, destacamos a Base Nacional Comum Curricular - BNCC (2017 e 2018), que visa dar uma orientação curricular padronizada para a formação dos brasileiros, portanto, define as dez competências gerais para a formação no decorrer da escolarização básica - Educação Infantil, Ensino Fundamental e Ensino Médio: 1 - Conhecimento; 2 - Pensamento científico, crítico e criativo; 3 - Repertório Cultural; 4 -Comunicação; 5 -Cultura digital; 6 - Trabalho e projeto de vida; 7 - Argumentação; 8-Autoconhecimento e autocuidado; 9 - Empatia e cooperação e 10 - Responsabilidade e cidadania (MOVIMENTO PELA BASE NACIONAL COMUM CURRICULAR, 2018, p. 2).

Segundo Gonçalves e Guerra (2018), a BNCC, apesar de se estabelecer em um momento distinto da década de 1990, em sua essência, permanece com os mesmos objetivos propalados nesse período. Logo, "[...] revestida de uma 'nova roupagem' as Competências Gerais da BNCC, postulam interesses socioeconômicos que visam a conservação de uma educação para o capital” (GONÇALVES, GUERRA, 2018, p. 35).

A BNCC, por meio das competências socioemocionais, indica o fortalecimento da avaliação em larga escala pela via do controle das emoções, nessa direção, "o documento orientador da BNCC explicita a necessidade da organização curricular por competências" (ZANOTTO, SANDRI, 2018, p. 136).

Os indicadores avaliativos pautados na cognição socioemocional possibilitam uma sujeição psíquica capaz de promover a aceitação ao "novo" mundo multifacetado do trabalho (ANTUNES, 2005). A ênfase no aspecto mercantil e concorrencial atinge todos os níveis de sociabilidade, assim, na educação, a avaliação em larga escala, por meio de competências socioemocionais, possui a função paradoxal de corresponder, pelos índices, duas demandas: a primeira deriva da compreensão de conceber a educação como mecanismo de preparação às imprevisibilidades do mercado, ao passo que, no segundo momento: sabe-se que, no âmbito da competitividade, a formação polivalente intensifica o processo de exploração e, consequentemente, do desemprego.

O mito, portanto, reside no fato de conceber a educação pelo viés educaçãotrabalho, trabalho-educação como demanda produtiva, ou seja, a retórica pragmática avaliativa considera os problemas econômicos resultantes da falta de preparo educacional (MORAES, 2003). Nessa condução, as competências socioemocionais operam na forma de controle social e condicionam psiquicamente e ideologicamente os interesses de manutenção do status quo social.

A proposta de avaliação mediante as competências socioemocionais é divulgada pelo Movimento pela Base Nacional Comum Curricular, por meio do documento intitulado "Dimensões e Desenvolvimento das competências Gerais da BNCC", do ano de 2018, com o apoio da organização - "Center for Curriculum Redesign" (CCR): 
Esta publicação tem o objetivo de apoiar redes, escolas e professores a compreender as Competências Gerais da Base Nacional Comum Curricular e como elas progridem ao longo da Educação Básica. A intenção é facilitar a sua inserção em currículos, práticas pedagógicas, materiais didáticos e processos de avaliação da aprendizagem (MOVIMENTO PELA BASE NACIONAL COMUM CURRICULAR, 2018, p. 1 - grifo nosso).

O processo de avaliação da aprendizagem não é dado aqui como um processo que possibilita a compreensão da "[...] realidade em seu movimento e em suas contradições materiais e sociais" (KLEIN; FAVORETO; FIGUEIREDO, 2013, p. 132). Antes, representa a pulverização das medidas avaliativas de caráter externo implementadas na educação brasileira nas últimas duas décadas (SHIROMA; ZANARDINI, 2019). Sobre isso, a própria BNCC esclarece:

Essa mesma tendência de elaboração de currículos referenciados em competências é verificada em grande parte das reformas curriculares que vêm ocorrendo em diferentes países desde as décadas finais do século XX e ao longo deste início do século XXI. É esse também o enfoque adotado nas avaliações internacionais da Organização para a Cooperação e Desenvolvimento Econômico (OCDE), que coordena o Programa Internacional de Avaliação de Alunos (Pisa, na sigla em inglês), e da Organização das Nações Unidas para a Educação, a Ciência e a Cultura (Unesco, na sigla em inglês), que instituiu o Laboratório Latino-americano de Avaliação da Qualidade da Educação para a América Latina (LLECE, na sigla em espanhol) (BRASIL, 2017, p. 16).

As competências socioemocionais se consolidam como um fenômeno da realidade social, cuja mediação se dá pela acumulação flexível do capital. Nesse sentido, o Banco Mundial elaborou o documento que se intitula, "Competências e empregos: Uma agenda para a juventude, 2018". Este, por sua vez, é um relatório centrado na avaliação dos principais desafios que os jovens enfrentam para alcançar a empregabilidade e a produtividade (BANCO MUNDIAL, 2018). O referido documento apresenta o viés fortemente comportamentalista, uma vez que os conceitos emanados estão incutidos de capacidades voltadas aos moldes comportamentalista de reprodução do sistema capitalista de produção:

As intervenções por meio de políticas podem melhorar o sistema educacional e de capacitação para oferecer competências relevantes e com base na demanda, bem como aumentar a eficiência do mercado de trabalho em termos de alinhamento entre trabalhadores capacitados e empregadores (BANCO MUNDIAL, 2018, p. 7 - grifo nosso). 
Todavia, mais que o controle exigido para a produção, manutenção e conservação de um sistema, a formação de capital humano está demandando competências resilientes aos indivíduos em relação aos desafios, obstáculos, esforço, crítica e sucesso dos outros (DWECK, 2017). Ou seja,

\begin{abstract}
Pensar modelos alternativos para desenvolver competências socioemocionais dos adolescentes trará o benefício de melhores comportamentos; assegurar um ensino técnico mais relevante, por meio de parcerias mais estreitas, e em diferentes níveis com o setor privado, desenvolverá competências técnicas alinhadas com as necessidades das empresas; e garantir que o modelo de escolaridade em tempo integral proporcione ensino de alta qualidade - por meio de professores com dedicação exclusiva, com melhor formação e atividades adicionais bem articuladas com o currículo - trará o benefício da melhor aprendizagem e da redução do abandono escolar (BANCO MUNDIAL, 2018, p. 32 - grifo nosso).
\end{abstract}

A BNCC do Ensino Médio, por exemplo, consubstanciando as necessidades expressas pelo Banco Mundial, define as competências como "[...] a mobilização de conhecimentos (conceitos e procedimentos), habilidades (práticas, cognitivas e socioemocionais), atitudes e valores para resolver demandas complexas da vida cotidiana, do pleno exercício da cidadania e do mundo do trabalho (BRASIL, 2018, p. 8 - grifo nosso).

A BNCC, por meio das competências socioemocionais reiteradas, propicia o acirramento das políticas de avaliação em larga escala no país. Assim, seus princípios estão associados ao desempenho almejado aos índices avaliativos internacionais e nacionais.

\title{
4. Considerações finais
}

Para analisarmos os desdobramentos das competências socioemocionais nas atuais políticas de avaliação e curricular, consideramos a base que originou a noção de competências, a partir dos anos de 1970, isto é, a reestruturação produtiva ou acumulação flexível. Sendo assim, compreendemos que as competências socioemocionais são oriundas das demandas da atual configuração do mercado de trabalho.

Tal configuração tem apresentado um crescimento nas atividades informais e temporárias, assim como as demandas para contratação para postos de trabalho, tem exigido trabalhadores com determinados comportamentos psicossociais como a flexibilidade, capacidade de trabalhar em equipe, lidar com conflitos e incertezas, entre outros elementos que passam a compor as denominadas competências socioemocionais.

Compreendemos que as demandas por competências socioemocionais no contexto da educação formal, atribui à escola a função de treinar os futuros trabalhadores para mercado de trabalho cada vez mais precário, isto é, discipliná-los 
para lidar com as oscilações e contradições econômicas de estar empregado ou não; de lidar com as incertezas, precarização e instabilidades do subemprego.

Ao ajustar a formação humana à lógica mercadologia por meio das politicas de avaliação e curricular, o Estado cumpre a sua função de educador no sentido de promover o consenso social, utilizando como parâmetro o mercado.

Ressaltamos que as problematizações que desenvolvemos no decorrer do texto, não negam a importância do desenvolvimento social e psíquico de cunho emocional dos sujeitos, mas questionamos a redução de tal desenvolvimento aos padrões mercadológicos, pelo fato de reduzir a formação a um rol de comportamentos sociais e emocionais padronizados a partir das necessidades do mercado.

\section{Referências}

ABATTI, Thamiris Zanchim. Estado da arte sobre competências socioemocionais e articulação com políticas de avaliação (2012-2017). 2018, 161 fls. Dissertação

(Mestrado em Educação), Universidade estadual do Oeste do Paraná - Campus de Cascavel, Centro de Educação, Comunicação e Artes. Programa de Pós-Graduação em Educação, 2018.

AFONSO, Almerindo Janela. Avaliação Educacional: Regulação e emancipação. Para uma Sociologia das Políticas avaliativas contemporâneas. - São Paulo: Cortez, 2000.

ANTUNES, Ricardo. O Caracol e sua concha: ensaios sobre a nova morfologia do trabalho. São Paulo: Boitempo, 2005.

BANCO MUNDIAL. Competências e Empregos: Uma agenda para a Juventude. Síntese de constatações, conclusões e recomendações de políticas, washington dc, 2018.

BANCO MUNDIAL. Aprendizagem para realizar a promessa da educação. Disponível em:

https://openknowledge.worldbank.org/bitstream/handle/10986/28340/211096mmP T.pdf?sequence=28\&isAllowed=y. Acesso em: 20 jul. 2019.

BRASIL. Base Nacional Comum Curricular (BNCC). Educação Infantil e Ensino Fundamental. Versão final. Brasília: MEC, 2017.

BRASIL. Base Nacional Comum Curricular (BNCC). Ensino Médio. Versão final. Brasília: MEC, 2018.

BRASIL. Inep. Diretoria de Avaliação da Educação Básica (Ed.). CARTILHA SAEB 2019. Distrito Federal: Inep, 2019.

BRASIL. Instituto Nacional de Estudos e Pesquisas Educacionais Anísio Teixeira. Ministério da Educação. Institucional. Disponível em: http://portal.inep.gov.br/web/guest/sobre-o-inep. Acesso em: 06 Jan. 2020.

DEITOS, Roberto Antonio. Políticas públicas: aspectos teóricos-ideológicos e socioeconômicos. Acta Sectarium. Maringá, v. 32, n.2, p. 209-218, 2010. 
DEITOS, Roberto Antonio; LARA, Angela Mara de Barros. EDUCAÇÃO PROFISSIONAL NO BRASIL: MOTIVOS SOCIOECNÔMICOS E IDEOLÓGICOS DA POLÍTICA EDUCACIONAL. In: ZANARDINI, Isaura Monica Souza; BATISTA, Eraldo Leme. Políticas Educacionais: Desafios e Perspectivas. Curitiba: CRV, 2019, p. 15-42.

DWECK, Carol S. Mindset: a nova psicologia do sucesso. Tradução - S. Duarte. 1a ed. São Paulo: Objetiva, 2017.

EVANGELISTA, O. Apontamentos para o trabalho com documentos de política educacional. In: ARAÚJO, R. M. L.; RODRIGUES, D. S. (Org.). A pesquisa em trabalho, educação e políticas educacionais. Campinas-SP: Alínea, 2012. p. 52-71.

FIGUEIREDO, Ireni Marilene Zago. A ARTICULAÇÃO ENTRE A REFORMA ECONÔMICA E A REFORMA EDUCACIONAL COM A SUSTENTAÇÃO DO MITO DA EDUCAÇÃO E DA IDEOLOGIA DA GLOBALIZAÇÃO. In: DEITOS, Roberto Antonio.; RODRIGUES, Rosa Maria. Estado, desenvolvimento, democracia \& políticas sociais. Cascavel: EDUNIOESTE, 2006, p. $105-120$.

FRIGOTTO, Gaudêncio. Educação e a crise do capitalismo real. São Paulo: Cortez, 2010.

GONÇALVES, Amanda Melchiotti; GUERRA, Dhyovana. COMPETÊNCIAS GERAIS DA BASE NACIONAL COMUM CURRICULAR E PARÂMETROS CURRICULARES NACIONAIS: CONTINUIDADE E CONSERVAÇÃO. Rev. Teoria e Prática da Educação, v. 21, n. 3, p. 27-39, Set./Dez. 2018.

GRAMSCI, Antônio. Caderno 13 (1932-1934): Breves notas sobre a política de Maquiavel. In: Cadernos do Cárcere, vol. 3. 3a ed., Rio de Janeiro: Civilização Brasileira, 2007. p. 12-109.

HARVEY, David. Condição Pós-moderna. 11a ed. São Paulo: Loyola, 2002.

SENNA, Instituto Ayrton. Competências socio emocionais: material para discussão.

KLEIN, Ligia R.; FOVORETO, Aparecida; FIGUEIREDO, Ireni M. Z.. Processo de tranformação/conservação social: uma reflexão a partir da "fábula dos porcos assados". Revista Teoria e Prática da Educação, v. 16, n. 3, p. 125-132, setembro/dezembro, 2013.

LIBÂNEO, José Carlos. Qualidade da escola pública: políticas educacionais, didática e formação de professores. Goiânia: Ceped Publicações; Gráfica e Editora América: Kelps, 2013.

LUCKESI, C.C. Avaliação da aprendizagem escolar. 17. ed. São Paulo: Cortez, 2005. LUCKESI, C.C. Avaliação da aprendizagem escolar. 14. ed. São Paulo: Cortez, 1995. MORAES, Maria Célia Marcondes. Recuo da teoria. In: MORAES, Maria Célia Marcondes. Iluminismo às avessas: produção do conhecimento e políticas de formação docente. Rio de Janeiro: DP\&A, 2003, p. 151-167. 
MOVIMENTO PELA BASE NACIONAL COMUM CURRICULAR. Dimensões e Desenvolvimento das Competências Gerais da BNCC. Center for Curriculum Redesign. 2018. Disponível em

http://movimentopelabase.org.br/acontece/competencias-gerais-de-bncc/. Acesso em 19 abr. 2018.

PEREIRA, Rodrigo da Silva. A política de competências e habilidades na educação básica pública: relações entre Brasil e OCDE. 2016. 285 f., Tese (Doutorado em Educação) - Universidade de Brasília, Brasília, 2016.

SAES, Décio Azevedo Marques de. DEMOCRACIA REPRESENTATIVA E DEMOCRACIA PARTICIPATIVA. In: DEITOS, Roberto Antonio.; RODRIGUES, Rosa Maria. Estado, desenvolvimento, democracia \& políticas sociais. Cascavel: EDUNIOESTE, 2006, p. 43-52.

SANDRI, Simone. AS REFORMAS E CONTEÚDOS DA INTERVENÇÃO DO EMPRESARIADO NA EDUCAÇÃO PÚBLICA. In: ZANARDINI, Isaura Monica Souza; BATISTA, Eraldo Leme. Políticas Educacionais: Desafios e Perspectivas. Curitiba: CRV, 2019, p. 71-94.

SENNA, Instituto Ayrton. Competências Socioemocionais em políticas públicas: Educação para o século 21. 2016. Disponível em:

http://porvir.org/especiais/socioemocionais/. Acesso em: 19 ago. 2019.

SHIROMA, Eneida Oto; ZANARDINI, João Batista. Avaliação na Educação Básica no Brasil: Políticas e contradições. In: Batista, Eraldo Leme; Zanardini, Isaura Monica Souza. Políticas educacionais: desafios e perspectivas. Curitiba: CRV, 2019, p. 117132.

ZANARDINI, Isaura Monica Souza. A REFORMA DA GESTÃO ESCOLAR E AS POLÍTICAS IMPLEMENTADAS NO BRASIL NA DÉCADA DE 1990. In: DEITOS, Roberto Antonio.; RODRIGUES, Rosa Maria. Estado, desenvolvimento, democracia \& políticas sociais. Cascavel: EDUNIOESTE, 2006, p. 121-136.

ZANARDINI, João Batista. Ontologia e Avaliação da Educação Básica no Brasil (19902007). 2008. 208 f. Tese (Doutorado) - Curso de PPGE, Universidade Federal de Santa Catarina, Florianópolis, 2008.

SHIROMA, Eneida Oto; MORAES, Maria Célia Marcondes; EVANGELISTA, Olinda. Política educacional. 4. ed. Rio de Janeiro: Lamparina, 2011.

ZANOTTO, Marijane.; SANDRI, Simone. AVALIAÇÃO EM LARGA ESCALA E BNCC: ESTRATÉGIAS PARA O GERENCIALISMO NA EDUCAÇÃO. Temas \& Matizes, Cascavel, v. 12, n. 23, p. 127-143, jul./dez. 2018 